\title{
Nucleic Acid Vaccines: Veterinary Applications
}

\author{
L.A. Babiuk, P.J. Lewis, S. van Drunen Little-van den Hurk,
}

S. TIKoo, and X. LiAnG

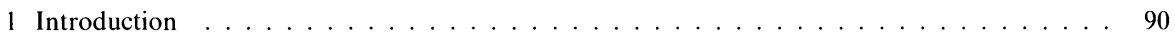

2 Impediments to Developing the Ideal Vaccine . . . . . . . . . . . . . . . . 91

3 Novel Approaches to Immunization . . . . . . . . . . . . . . . . . . . . . . 93

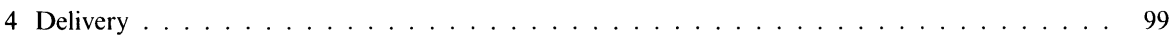

5 Regulatory Issues . . . . . . . . . . . . . . . . . . . . 100

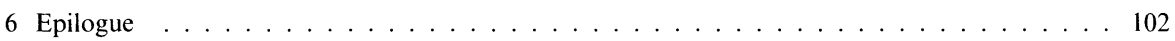

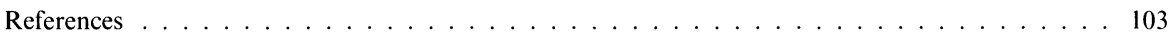

\section{Introduction}

Few would disagree that immunization to prevent infectious diseases has significantly impacted the economics of livestock and poultry production globally. Unfortunately, even with these successes, there is a need to extend the impact of such vaccination programs since economic losses continue to plaque producers and in some instances limit the areas of livestock production or reduce the economic return to producers by limiting the export of genetic stock. To increase animal productivity, infectious diseases have been the primary targets for vaccination, although more recently, ectoparasites are also becoming a target for immunization.

Most currently licensed vaccines are produced by conventional technologies which have not changed significantly from those used by Jenner or Pasteur 200 and 100 years ago, respectively. Due to the inherent disadvantages of these conventional vaccines, novel strategies are being developed to produce a new generation of vaccines with improved efficacy, ease of administration and fewer side reactions. These new generation vaccines have been made possible by recent advances in molecular biology and our understanding of virulence genes, identification of specific proteins or glycoproteins involved in inducing protective immunity, as well as an appreciation of host-pathogen interactions and host immune responses to various pathogens. This is especially important for those pathogens which cannot

Veterinary Infectious Disease Organization, 120 Veterinary Road, Saskatoon, Saskatchewan S7N 5E3, Canada 
be cultured easily in vitro. The first vaccine produced by this technology, for any species, was a vaccine designed to control hepatitis B. In this case, the hepatitis B surface antigen was produced in yeast (VALENZuELA et al. 1982). This was followed shortly thereafter by the production of the world's first genetically engineered licensed subunit vaccine for animals when the Pasteurella hemolytica leukotoxin was cloned, expressed in E. coli and shown to be effective in reducing respiratory disease in cattle (PotTer et al. 1990). Subsequently, the licensing of a live, gene deleted vaccine for pseudorabies virus not only provided for a safe live vaccine, but also allowed for the implementation of a immunization-eradication program to eliminate pseudorabies virus (KIT et al. 1987). These initial successes have lead to the licensing of a number of live recombinant vaccines such as vaccinia rabies glycoprotein recombinants (PASTORET et al. 1988). However, even as this new generation of vaccines is being developed and accepted by regulatory agencies, commercial companies and the general public, a new approach to immunization has emerged which has the potential to complement these new generation vaccines and in some cases supplant them completely.

The third generation of vaccines is based on the observations that naked nucleic acids, when introduced into cells, can function and express sufficient proteins in vivo to evoke an immune response (TANG et al. 1992; Cox et al. 1993; ULmer et al. 1993). Following these initial observations, the phenomenon of genetic immunization has been confirmed with genes encoding for viral, bacterial, parasitic, and tumor antigens. Furthermore, this phenomenon appears to work in many species including those of veterinary importance (WILLIAMS et al. 1991; TANG et al. 1992; Cox et al. 1993; Davis et al. 1993; Donnelly et al. 1993; FynAN et al. 1993; Robinson et al. 1993b; HofFmAnn et al. 1994; Lowrie et al. 1994; XIANG et al. 1994; Xu et al. 1994). The present review will summarize the practical problems associated with vaccine development for veterinary species as well as the application of genetic immunization to overcome some of these problems.

\section{Impediments to Developing the Ideal Vaccine}

The ideal vaccine for animals would be one that provides greater than $90 \%$ efficacy following a single administration of the vaccine. Furthermore, this protection should occur rapidly, within 2 weeks of administration, and should be of long duration such that animals would not need to be re-immunized. This would not only reduce the cost of repeated immunization but also reduce the level of pathogen circulation in the environment. Even though it may be possible to achieve success under experimental conditions, consideration must be given to the different management conditions employed in different parts of the world. Furthermore, epidemiology and pathogenesis of the specific agent will influence the type of vaccine that will be effective as well as the effectiveness of different vaccination regimes. For 
example, in cattle and pigs, enteric infections caused by rotavirus, coronavirus and $E$. coli occur in the first few weeks of life. Since it is not possible to induce immunity within 2-3 days of birth, with any vaccine, the main focus is to immunize the mother who then transfers antibody in her milk to the offspring. This antibody coats or bathes the gastrointestinal tract of the young and prevents infection. Thus, the ideal vaccine for this group of pathogens would be one that is administered to the dam, resulting in high levels of antibody in the dams milk for 3-4 weeks (BABIUK et al. 1984). To achieve this, immunization regimes will be required to stimulate high levels of antibody in the milk of the mothers to protect the offspring. Unfortunately, with early weaning practices in pigs, animals are removed from the mothers while they are still susceptible to infection. Thus, immunization regimes will need to be developed whereby passive immunity provides early protection while active immunity is being developed. Unfortunately, passively acquired antibody also interferes with active immunization by conventional vaccines. Thus, novel approaches to overcome interference by passive antibody will need to be developed. Recent studies have demonstrated that genetic immunization has the potential to overcome interference by passive antibody.

In poultry, infection occurs shortly after hatching. Thus, producers have immunized layers, who then transfer antibody to the eggs thus protecting the chicks from infections early in their lives. This is especially important for diseases such as infectious bursal disease, which during the first few weeks of life destroys the bursa of Fabricius and subsquently reduces the bird's ability to develop immunity to many pathogens because the number of B cells is reduced. An alternate approach to provide early immunity is to immunize day-old chicks. Unfortunately, some diseases occur before the chick develops significant levels of immunity. To try and induce active immunity early, Embrix (Durham, NC) has developed a method to introduce vaccines into chicks prior to hatching (in ovo vaccination). This new egg inoculation technique also reduces the amount of handling required for mass immunization of poultry.

In the case of bovine respiratory disease, management systems vary around the world with economical losses often occurring following weaning, movement and confinement of animals. This type of management system not only stresses the animals, thereby making them more susceptible to infections, but also provides an excellent opportunity for simultaneous exposure to a variety of different pathogens (BABIUK and CAMPOS 1992). In many cases these pathogens act synergistically to increase the severity of respiratory infection. Vaccination at entering the feedlots does not provide sufficient time for the development of immunity and disease prevention. Reduction in infection and economic losses could be achieved if preshipping vaccination regimes were adopted. If vaccination could be implemented early, this would reduce infections, but unfortunately animal husbandry practices prevent this type of approach from being implemented.

In many cases it is unsatisfactory to introduce vaccines by intramuscular or subcutaneous routes since this requires needle injection. In commercial settings the rather large number of animals that are immunized at any one time, which can involve restraint difficulties, can lead to pathologies such as: injection site necrosis, 
focal adjuvant or bacterial mediated myositis, abcessation, and broken needles which may remain deposited in the muscle of the animals. This affects meat quality and safety. Thus, it is imperative that better vaccines and delivery systems are developed which reduce these unwanted side effects. Delivery of vaccines orally or intranasally should remove some of these unwanted side effects. A further advantage of this type of delivery is that most infections enter via a mucosal surface, thus, immunity at these sites would prevent initiation of the infection. In poultry, the sheer number of animals involved in any single enterprise favors delivering the antigen in water, by aerosols, the food or in ovo. In this species the ideal vaccine would be one that takes into consideration ease of administration while ensuring that mucosal protection is induced.

Another very important consideration in veterinary medicine is the cost. This is especially important for poultry and in developing countries. Vaccines for poultry must be produced for pennies per dose. This is in contrast to vaccines for other mammalian species which may sell for $\$ 0.50-\$ 1.00$. In humans similar vaccines could sell for $\$ 10.00-\$ 30.00$. This economic difference clearly indicates the impediments to developing effective vaccines for some veterinary species. Thermal stability is required in most situations where refrigeration is not possible to maintain the vaccines from manufacturing to administration. This is especially important in developing countries where a cold chain is not always guaranteed or for those vaccines which are administered in bait and may be present in the environment for extended periods of time before infection (PAstoret et al. 1988).

In addition to developing mucosal immunity the vaccine should develop a balanced immune response inducing both humoral and cellular immunity. In all instances, vaccines need to be genetically stable with no chance of reversion to virulence in causing clinical signs either in the vaccinated animals or in unvaccinated contacts. Immunosuppression or interference with immunity to other vaccines given simultaneously has been shown to occur, but should be minimal or nonexistent (HARLAND et al. 1992; Kerlin et al. 1992; INOKUMA et al. 1993; Theodos et al. 1993; WiKel et al. 1994). Since many vaccines are administered simultaneously, vaccine architecture and compatibility are becoming very important considerations (Morein et al. 1987; Hughes et al. 1991; Hughes et al. 1992b; EAsT et al. 1993). Although at present many adjuvants contain mineral oils, these will need to be replaced in the future since these oils are nonmetabolizable and leave residues at the injection site. All of these factors must be considered in developing vaccines for veterinary species.

\section{Novel Approaches to Immunization}

Due to the need for better vaccines for many diseases, new approaches are being developed for vaccine production and delivery. These approaches are based on the observation that pathogens possess a variety of different proteins, some of which 
are important in inducing protective immunity whereas others are of no relevance in protection and can actually be detrimental by virtue of their ability to induce immunosuppression or even enhance infectivity (PEDERSEN et al. 1986; Nick et al. 1990; Olsen et al. 1992; Harland et al. 1992; Kerline et al. 1992; InOKuma et al. 1993; WiKel et al. 1994). The thrust over the past decade has been to develop either subunit vaccines containing only the most critical proteins involved in inducing protection or live attenuated vaccines by deleting specific genes involved in virulence with a low probability of back mutation and reversion to virulence (KIT et al. 1985). This should ensure safer vaccines that can be delivered by the oral or mucosal routes and stimulate both cellular and humoral immunity at mucosal sites, thereby blocking the establishment of an infection. Even more exciting is the possibility to use these genetically engineered vectors to carry multiple antigens from other pathogens, thereby providing the opportunity for immunizing animals against a variety of pathogens with a single vaccine (PASTORET et al. 1988; YILMA et al. 1988; ZIJL et al. 1991; WhitTon et al. 1993). This approach has many advantages over multiple vaccinations or combination vaccines in which one pathogen may interfere with immune responses to the other. One of the best examples of such a genetically engineered vaccines is vaccinia rabies glycoprotein recombinants, which are used to control rabies in wildlife (PASTORET et al. 1988).

Recent progress in molecular biology, protein engineering and immunity has had a very significant impact on our ability to identify protective components of many pathogens including those which stimulate $\mathrm{T}$ and $\mathrm{B}$ cell responses. This reductionist approach has proven to be successful for both viral and bacterial pathogens and more recently with "concealed" antigens of ectoparasites (OPDEBEECK 1994). However, these studies have also indicated that the form of antigen and its formulation have a significant influence on vaccine efficacy and on the duration of the immunity (van Drunen LitTle-van den Hurk et al. 1993a). This is especially important for those pathogens in which cell-mediated or mucosal immunity is critical. In viral infections, the major targets for immunity are often surface glycoproteins. Since glycosylation and conformational properties of the glycoprotein are critical for inducing the appropriate immune response, they must be produced in mammalian cells. Presently this is relatively expensive and even if the protein is produced in mammalian cells the immune response to exogenously delivered antigen is not the same as to endogenously produced antigens.

Since the form of antigen is critical for inducing the appropriate immune responses as well as for long-term immunity in animals, we attempted to determine whether immunity induced by genetic immunization would function in livestock. This hypothesis was based on earlier studies in which transformation of cells in vitro occurred following injection of purified polyomavirus naked DNA (Atanasiu 1962). These studies were further extended by WolfF (1990), who clearly indicated that injection of plasmid DNA into muscle cells of mice resulted in expression of foreign genes in the cells for extended periods of time. This was latter confirmed by TANG et al.(1992) and numerous other workers using mouse model systems. These studies also clearly indicated that both cell mediated immunity and humoral immunity were induced following in vivo introduction of plasmid DNA. 
As a result of expression of these genes in vivo, immunity to foreign proteins develops and may remain for extended periods of time (Ulmer et al. 1993). Since uptake and expression in vivo has been observed with various genes in different species such as fish, chickens, dogs, cats, monkeys and cows it appears to be an universal phenomenon which would have application in all veterinary species (Williams et al. 1991; Weiss et al. 1992; Donnelly et al. 1993; Fynan et al. 1993; Robinson et al. 1993b; Hoffmann et al. 1994; Lowrie et al. 1994; XiAng et al. 1994; Xu et al. 1994; Ulmer et al. 1994a).

In an attempt to demonstrate the utility of this approach in veterinary species our laboratory has focused on developing vaccines against viruses for cattle (Cox et al. 1993). More specifically we have focused on bovine herpesvirus-1 and bovine rotavirus (BABIUK et al. 1996). The following section will describe some of our observations and describe possible extensions of our studies to other pathogens of veterinary interest.

Vaccines to bovine herpesviruses can serve as a model for herpesvirus infections in other species as well as help reduce significant losses in the cattle industry due to infection by this virus (van Drunen LitTel-van DEN Hurk et al. 1993b; TIKOO et al. 1995). Since the surface glycoproteins are critical for attachment and entry of the virus into host cells, antibody directed against these glycoproteins should interfere with infection. To test this hypothesis we purified glycoprotein B (gB), $\mathrm{gC}$ and $\mathrm{gD}$ using monoclonal antibodies and used them as experimental vaccines in cattle (BABIUK et al. 1987). In all cases the purified protein induced neutralizing antibody and, more importantly, calves were protected from infection. Expression of the glycoproteins in different expression systems clearly indicated that glycosylation or conformation of the glycoprotein was important for inducing the most effective immune responses (VAN DRUNEN LitTEl-van DEN HuRK et al. 1993a). Glycoproteins produced in E. coli did not induce antibody to the epitopes involved in neutralization and therefore was not effective in preventing virus infection. These studies also demonstrated that immunity induced by subunit vaccines was not life-long. Therefore we postulated that immunization of cattle with a plasmid encoding the glycoproteins should result in immunity to the important epitopes and, if the plasmid persisted, it should induce immunity of long duration.

Although various promoters have been used to drive gene expression in vivo, our initial studies used the Rous sarcoma virus (RSV) enhancer/promoter (Cox et al. 1993). This expression cassette proved to be satisfactory, but we anticipate that improvements made in plasmid construction will continue to improve the efficiency of expression in vivo. Since many viral glycoproteins are toxic to cells, as is $\mathrm{gD}$, we constructed a number of plasmids expressing different forms of $\mathrm{gD}$ (TiKoo et al. 1990). We were especially concerned that if full length gD killed the transfected cell in vivo, the quantity and duration of protection would not be sufficient to induce long-term immunity. Thus we constructed a plasmid containing the entire gD gene and a second plasmid containing the gD gene without the transmembrane anchor (Тıкоо et al. 1993). This latter plasmid would secrete the gene product into the extracellular milieu. The third construct lacked the signal sequence and was designed to help determine the possible role 
of the muscle cell in antigen presentation. In all instances, when the plasmids were introduced into mice, immunity developed (BABIUK et al. 1995a). However, when the antigen was retained in the cytosol there was a delay in the immune response and the magnitude of the immune response was slightly reduced.

Immunization of cattle with the plasmid encoding the full length $\mathrm{gD}$ resulted in the development of antibody which could neutralize virus. In addition, plasmid immunized cattle developed lymphocyte proliferative responses similar in magnitude to those found in cattle immunized with purified gD. Based on the observation that serum neutralizing antibodies and cell mediated immune responses were of the magnitude that was previously shown to be protective in cattle, we challenged the animals with an aerosol of a virulent field strain of virus. All control animals exhibited clinical signs characteristic of infection and shed virus for a period of 8-10 days. In contrast, animals immunized with plasmids encoding gD only exhibited mild clinical signs and shed significantly less virus for a much shorter period of time. These results are interesting, since plasmids were introduced via the intramuscular route. If the plasmids were introduced by the intranasal route, one would expect a more significant mucosal response which might totally eliminate virus infection and shedding.

Most reports to date using intramuscular injection of plasmids suggest a polarized Th1 response as measured by the cytokine profiles of purified lymphocytes (BABIUK et al. 1995a). In mice and cattle, immunization with plasmids encoding gD also suggested that a Thl titer response was produced. These results are important for two reasons. (1) Cell mediated immunity is considered to be critical for recovery from herpes infections (BABIUK et al. 1995b). (2) In BHV-1 especially, interferon- $\gamma$ plays an important role in activating macrophages to kill BHV-1 infected cells (CAmpos et al. 1989). Thus a Th1 response is considered to be critical in this disease.

Protection of cattle from BHV-1 infection following immunization with plasmids was extremely encouraging for a number of reasons. First, the observation that DNA immunization can induce immunity in a large animal indicates that it should be possible to adapt this approach to many species of veterinary importance. Second, this method of vaccination provides an opportunity to elicit immunity of long duration against diseases of all species (Michel et al. 1995). For example, horses need to be immunized two to three times per year to protect them against equine rhinotracheitis virus (equine herpes-1). Trainers are generally reluctant to immunize horses during the racing season. Thus, horses often suffer from respiratory disease. Combining an equine herpesvirus plasmid vaccine with plasmids encoding equine influenza virus should dramatically reduce respiratory distress at race tracks. Thus, combining the plasmids encoding for protective antigens of these different pathogens should be effective in horses. Whether improvements in delivery can be made to achieve long-term immunity with a single injection remains to be determined. DNA immunization of poultry and other species against influenza virus with genes encoding for the hemagglutinin and nuclear protein have already been shown to be effective (RoBINSON et al. 1993a; WeBSTER et al. 1994; Ulmer et al. 1994b; Donnelly et al. 1995). 
Pseudorabies virus of pigs is also a potential target for DNA immunization. Presently, many countries are trying to eradicate pseudorabies virus. DNA immunization can be used as a "marker" vaccine such that differential tests can be developed in parallel. A marker vaccine, which only induces antibody to a single glycoprotein, can allow the development of tests to differentiate infected animals from latent carriers. DNA immunization provides such an opportunity. Similar approaches might be applied to tuberculosis or brucellosis against which protection could be provided by vaccination while still allowing the identification of carriers.

The observation that DNA immunization can be effective with viruses and bacteria provides an excellent opportunity to vaccinate animals against multiple viral and bacterial pathogens simultaneously. Furthermore, in modern livestock practices, immunization can only occur at specific times when animals are handled.

Unfortunately, early in the animal's life, a time when it is amenable to vaccination, high levels of maternal antibody are present which interfere with conventional vaccination. The fact that plasmids may persist and might induce immune responses in the presence of passive antibody provides an excellent opportunity to immunize animals earlier in life (BABIUK et al. 1996; Ertl, personal communication).

In addition to inducing immune responses to infectious diseases, DNA immunization also has the potential for control of ectoparasites. Studies have shown that reducing the level of symbiotic bacteria, which supply nutrients to the arthropod, can be a method to reduce arthropod fertility. An example of such an effect is with the Tsetse fly, in which symbiotic bacteria help digest blood meal components and supply nutrients to the Tsetse fly (NogGe 1978). If it was possible to disrupt this symbiotic relationship then the survival of the Tsetse fly would be dramatically reduced. Immunization of animals against the symbiotic bacteria would help neutralize their biological activity in vivo or neutralize the digestive enzymes produced by these bacteria (ALLEN 1994). This should result in starvation and death of the parasite even if it is engorged. Thus, the overall effect would be a reduction of Tsetse fly population.

Immunization of rabbits against mid-gut antigens of mosquitoes demonstrated lower survival rates in mosquitoes fed on immunized rabbits versus mosquitoes fed on normal rabbits (Alger et al. 1972). Similar results were reported when mid-gut antigens of ticks were used to immunize cattle (ALLEN et al. 1979). These studies lead various investigators to speculate that it should be possible to use these concealed antigens as vaccines (WILLADSEN et al. 1993). Concealed antigens do not normally induce immune responses during ectoparasite infestation since they are rarely exposed to the immune system. However, if the host contains antibodies to these antigens in the blood, when the ectoparasite obtains a blood meal, these antibodies interact with the concealed antigen in the gut and in combination with complement may result in lysis or disruption of gut cell function. This results in death of the ectoparasite or a dramatic reduction in its reproductive capacity. Recently an $86 \mathrm{kDa}$ glycoprotein has been identified in ticks which is part of the concealed antigen repertoire. When this antigen was introduced into cattle who were subsequently exposed to ticks, the vaccinated animals had fewer surviving ticks, and these showed reduced engorgement and dramatic reduction of egg pro- 
duction capacity (WILLADSEN et al. 1988). Similar approaches have been used for controlling the sheep blow fly, in which a PM44 protein from the larval gut was identified as the potential concealed antigen (EAST et al. 1993; WILLADSEN et al. 1993; EISEMANN et al. 1994). Since many of these antigens are glycoproteins, administration of genes encoding these glycoproteins in plasmids should induce very high levels of immune responses to the appropriate epitopes. Although there are no reports in the literature indicating that DNA immunization works with concealed ectoparasite antigens, there is confidence that such an approach should work, especially for those ectoparasites which primarily feed on a single host. Thus, if it was possible to immunize all of the hosts in a specific environment it should dramatically reduce the ectoparasite load. If these ectoparasites also serve as transmission vectors for infectious agents, there should be a double benefit in reducing economic losses not only to the ectoparasite but also to the infectious agent transmitted by the parasite.

The type and magnitude of the immune response are influenced not only by the antigen, but also by the micro-environment where the response is being initiated. This micro-environment is influenced by the constellation of cells that are interacting at that site, their level of stimulation and the cytokines they produced. This is best demonstrated by the observation that administration of antigen to mucosal surfaces induces immunity at mucosal surfaces whereas systemic immunization induced systemic immunity. Thus, introduction of a plasmid into mucosal sites, by a gene gun, should induce higher mucosal immune responses than if the genes are introduced intramuscularly or intradermally at sites other than mucosal surfaces. Furthermore, it appears that introduction of plasmids intramuscularly induces primarily Th1 responses with $\mathrm{IgG} 2 \mathrm{~A}$ as the major antibody isotype. In contrast, gene gun administration favors a Th2 type response and predominantly an IgG1 isotype response (Robinson, personal communication). Thus, if a specific isotype or level of antibody is critical for a specific pathogen, then the appropriate route of administration needs to be chosen. In addition, it may be desirable to drive the immune response by co-administration of cytokines. Since the action of cytokines is extremely short lived, most cytokines need to be administered multiple times to act as adjuvants (Hughes et al. 1991, 1992a). The administration of plasmids encoding different cytokines could overcome the need for multiple administration of cytokines or slow release delivery systems. To test this hypothesis we co-administered plasmids encoding gD with granulocyte/macrophage colony-stimulating factor (GM-CSF). Results from these experiments suggest that the magnitude of the immune response can be increased by co-administration of GM-CSF with plasmids encoding gD (BABIUK et al. 1996). Since genes coding for many of the animal cytokines have already been cloned, including some cytokines from poultry, the potential use of cytokines to enhance as well as to focus immune responses appears to be feasible for many species. In addition to enhancing immune responses by coadministration of genes encoding cytokines and pathogens the immune modulation induced by these cytokines may provide early protection to animals while immunity is being developed to the specific pathogen of interest. 


\section{Delivery}

DNA immunization provides a number of advantages regarding delivery which should be adaptable to various species and induction of various types of immune responses depending on the agent and the animal which is being immunized. If mucosal immunity is desired, delivery by a gene gun into the mucosal surfaces may be desirable. Although no published reports are available in which delivery to mucosal surfaces with a gene gun has been achieved, Agricetus (Madison, WI) is investigating delivery of such genes to the mucosal surface of the oral cavity of dogs (Haynes, personal communication). This is a relatively easy procedure with minimum discomfort to the animal. Delivery of genes via a gene gun involves coating gold particles with the plasmid of interest. A major advantage of using gold particles to deliver the gene is that elemental gold is inert, the DNA appears to be protected from degradation and is administered directly into the cell. Results to date indicate that immune responses are induced with submicrograms quantities of DNA. This is at least an order of magnitude less than if direct injection is used. Other needle-less injection devices, such as those used for insulin injection in humans, do not use gold particles. In these devices the gene is administered in saline or other liquid vehicles or excipients (DAvis et al. 1993). All of these devices need to administer the gene to areas of the body that are devoid of significant body hair and have relatively thin stratum corneum and epithelial layers. In ruminants and other mammals such areas include the oral or nasal mucosa or caudle fold. Another potential site for injection is the inner surface of the ears. The ear appears to be especially attractive since reports have indicated that immunity develops quickly after introduction of genes into the ear (Johnston, personal communication). A further advantage of injection into the ear is that it may induce mucosal immunity due to the shared lymphatic drainage with the nasal mucosal site (GAo et al. 1995). An additional advantage of using the ear as a site of immunization is ease of administration. It is very difficult to restrain large animals to administer vaccines intranasally. This was very evident following the introduction of live intranasal vaccines to cattle. Following administration of the vaccine to a few hundred animals, operator fatigue sets in and the vaccines are not administered properly. Similar concerns will arise with genetic immunization. Although previously we indicated needle injection as being less acceptable, due to broken needles and injection site reactions; subcutaneous injection, even by needles, into the ear would dramatically reduce these problems since the ear is of minimal value to the carcass.

Presently, direct injection into all species requires significantly larger quantities of DNA to induce an immune response than if administered by a gene gun. The reason for this may be degradation of the plasmids before they are taken up by the cells in vivo and transported to the nucleus. To improve the transfection efficiency various groups are developing novel cytofectins or polymers which interact with the DNA to protect it and assist in DNA transport to the nucleus (FELGNER 1995; HAENSLER et al. 1993; Longley et al. 1995). These novel cytofectins should dramatically reduce the quantity of DNA required for injection thereby making the 
procedure extremely effective and economical, possibly approaching that of the gene gun.

Although developments in the area of cytofectins are progressing rapidly it may be possible to combine two technologies, genetic immunization and amplicons to further improve delivery and immunity (Ho 1994). Using amplicons, genes can be amplified, packaged and introduced into host cells. Since herpes viruses can package approximately $150 \mathrm{~kb}$ of DNA within the capsids, multiple foreign genes could be administered with a single vaccination. The viral capsids would protect the DNA extracellularly, allow transport to the nucleus and enhance transfection efficiency dramatically. Delivery of plasmids into mammalian cells by bacterial vectors may also be possible. The economics of producing such vaccines would be significantly better than those of present vaccines since a single amplicon or bacterial vector could induce immunity to a large number of pathogens simultaneously. Furthermore, both of these delivery systems could be used to deliver genes to mucosal surfaces. Techniques for lyophilizing and preserving modified live viruses and bacteria are already in place, thus the downstream processing and vaccine formulation steps for amplicons would not need to be modified dramatically compared to those presently being used by the vaccine manufacturers.

Amplicons would not only be effective delivery vehicles for mammalian species, but would also fit into the in ovo injection system being used by Embrix. In this case the amplicons could be based on Marek's disease which act as the vehicles to introduce genes into the embryo in ovo. This would overcome the impediment of direct DNA injection into embryos in ovo in which introduction of the DNA would need to be administered into the embryo. Presently this appears to be a very difficult if not an impossible task. Using the amplicon it would be possible to deliver the DNA into the embryo and more importantly deliver multiple genes to ensure that the chick is immunized to all of the desired pathogens even prior to hatching.

\section{Regulatory Issues}

As with any new technology the regulatory agencies and society must ensure both the short- and long-term safety of products licensed for use. Although regulatory agencies evaluate each new vaccine on a case by case basis, some generic information will be important in providing a level of comfort for regulating all nucleic acid vaccines. The first major concern raised is whether the DNA used in the vaccine can integrate into the host genome and subsequently produce deleterious affects to the host. Integration may result in insertional mutagenesis and activation of oncogenes, inactivation of tumor suppressive genes or chromosomal alterations and rearrangements. Since any one of these events could lead to altered cell growth and tumors this would be unacceptable for any vaccine. In the case of integration, numerous attempts have been made at demonstrating whether integration occurs or not. To date, evidence suggests that integration is an extremely rare event, if it 
occurs at all, with the presently used plasmids. Recent progress in developing new plasmids with minimal or no homology to host sequences as well as utilizing minimal sequences required for in vivo function should further reduce the chance of integration. Thus, it appears that integration and activation of oncogenes by plasmid immunization will be extremely remote and therefore should not be a major concern for licensing DNA vaccines for animals.

The quantity of DNA that remains in the host following genetic immunization is very low and the risk of transfer from the immunized animals to humans consuming the meat is even lower. Therefore, the risk to humans consuming meat from DNA immunized animals should not be an issue. However, to investigate whether tissue containing plasmid DNA may be transferred to individuals consuming the meat, calves were injected with plasmid DNA encoding for bovine herpesvirus-1 gD and 3 weeks later the injection site was excised. This tissue was then fed to rats and several organs and tissues were tested for the presence of $\mathrm{gD}$ specific sequences using the polymerase chain reaction. In no instance could we detect any evidence of $\mathrm{gD}$ sequences in the animals that consumed tissue injected with plasmid DNA (unpublished results). These results provide a level of confidence that humans consuming meat from animals immunized with plasmids would not be at risk. This appears very logical since a few plasmids that may persist in the tissue of the immunized animals would further be degraded following slaughter, processing and digestion.

Previously, we stated that reactogenicity of vaccine and adjuvant residues was of concern for conventional vaccines. Similar concerns must be addressed with genetic vaccines. Since many of the genetic vaccines being tested to date are either administered without any carriers (intramuscular injection) or by biolistic bombardment with inert gold particles there does not appear to be any local reactogenicity with any of these vaccines reported to date. This is very interesting, especially since the plasmid appears to persist, at least in some instances, with continuous stimulation of the immune system. Investigations to date with numerous plasmids do not show any granuloma formation and only minimal leukocyte infiltration. This is critical for food-producing animals, as the quality of the food is of major concern.

Since there was no evidence of systemic toxicity even when DNA concentrations as high as $1 \mathrm{mg}$ were injected, immunization of pregnant animals should not result in any adverse side affects. Unfortunately, no reports have yet been published in which large doses of plasmid DNA were injected into pregnant animals. An effect of plasmid immunization on reproduction must be performed to determine whether there are any adverse affects or toxicity to the fetus and whether naked DNA can be transferred to the fetus.

Early in the discussion regarding DNA immunization, the concern was raised whether immunization with DNA, which persists, would induce anti-DNA antibodies. It is becoming accepted that it is extremely difficult to induce anti-DNA antibodies, especially if the DNA is not injected with strong adjuvants. Since food-producing animals generally do not live long between immunization and slaughter this concern appears to be minimal. We anticipate that DNA vaccines 
for veterinary species will be licensed before human vaccines, and the experience with large numbers of veterinary species will provide a level of comfort that antiDNA antibodies do not develop. This will provide a level of confidence for application of this technology to human vaccination in the future.

The continued expression of an antigen in vivo may induce unexpected consequences such as tolerance or exhaustion of the immune response or, alternatively, autoimmunity or hyperimmunity. Experiments conducted to date suggest that this does not occur, but once again, extensive experience in veterinary species should provide a level of confidence for use of this technology in long-lived species such as humans, in which reversal of adverse reactions would be difficult.

Scale-up, production and purification schemes for DNA vaccines will need to meet the same quality control parameters that other licensed vaccines do today. Thus the product will need to be consistent from batch to batch, both biochemically and genetically. Obviously, impurities in the final product will need to be negotiated with the regulatory agencies; however, certain acceptable parameters are already well established. For example, removal of bacterial by-products, such as endotoxin, is a common practice in vaccine development. In contrast, subunit vaccines require the removal of DNA from the vaccine. Obviously, for DNA vaccines this requirement will need to be modified.

In summary, even though a number of early concerns were raised regarding the potential detrimental effects following DNA immunization, these have not been borne out. Based on these findings, it appears that very few regulatory issues will be hindrances to the licensing of this new generation of vaccines for veterinary species. Furthermore, the experience we gain in veterinary species should have a significant impact on raising the level of comfort for applying this technology to human medicine.

\section{Epilogue}

The advances in the development of new vaccines for improving animal health have been expedited by the application of biotechnological techniques and our understanding of the host responses to foreign antigens. In parallel with the applications of molecular biology there have been advances in immunology which are further assisting us in our understanding of the host response to immunizations and how these responses can be enhanced. Advances in protein engineering, epitope mapping and understanding the roles of $\mathrm{T}$ and $\mathrm{B}$ cell epitopes as well as the requirements for specific conformational constraints in inducing immune responses are allowing the development of more efficacious vaccines which stimulate the appropriate immune response. One of the most recent developments in this area is the ability to induce immune responses with plasmids encoding specific protective proteins. By introducing the gene directly into the animal many of the downstream processing steps required for the development of vaccines, adjuvants and 
formulation are completely eliminated. This makes it extremely attractive for immunizing animals against various diseases and ectoparasites simultaneously. Our ability to re-engineer genes to reduce secondary structure and improve codon bias combined with developments in the area of promoters and delivery vehicles to increase the level of expression in vivo have the potential to dramatically reduce the quantity of DNA required for induction of an effective immune response. Thus, if an immune response can be induced with doses of $1 \mu \mathrm{g}$ of DNA, animals could be immunized with 10-20 different plasmids simultaneously, provided that no interference occurs between such genes. Clearly, doses as high as $1000 \mu \mathrm{g}$ do not cause any adverse reactions in animals. A further advantage of plasmid immunization is that each of the individual plasmids could be manufactured and then blended into different combinations of vaccine depending on the management conditions and areas of the globe where the vaccine is being used.

Although the exact mechanism whereby DNA uptake occurs following intramuscular or intradermal injection and which cells actually present antigen are not fully understood, most studies to date suggest that such administration favors a Th1 response. Thus, in parasitic infections and in some bacterial infections, such as mycobacterium, in which a Th1 response is critical, injection may be the most attractive way of vaccination. In contrast, in those cases in which a Th2 response is favored, administration by the gene gun may be more appropriate. Thus, it is envisaged that DNA immunization will allow us to stimulate the type of response which is desired. Furthermore, using plasmids encoding different cytokines it should not only be possible to enhance immune responses, but potentially to tailor the immune response to a Th1 or Th2 type. Finally, since passive immunization may not interfere with development of immune responses following genetic immunization, this new technology should allow genetic immunization to be used under a variety of management conditions including immunization of very young animals. Based on the exciting results observed during the last few years using genetic immunization, we are confident that the vaccines of the future will be much more efficacious and safer than presently licensed vaccines.

\section{References}

Alger NE, Cabrera EC (1972) Increase of death rate of Anopheles stephensi fed on rabbits immunized with mosquito antigen. J Econ Entomol 65:165-168

Allen JR (1994) Host resistance to ectoparasites. Rev Sci Tech Off Int Epiz 13(4):1287-1303

Allen JR, Humphreys SJ (1979) Immunization of guinea pigs and cattle against ticks. Nature 280: 491-493

Atanasiu P (1962) Production de tumeurs chez le hamster par inoculation d'acide desoxyribonucleique extrait de cultures de tissues infectees par le virus de polyome. Acad Sci 254:4228-4230

Babiuk LA, Sabara MI, Hudson GR (1984) Rotavirus and coronavirus infections in animals. Prog Vet Microbiol: $80-120$

Babiuk LA, L'Italien J, van Drunen Littel-van den Hurk S, Zamb T, Lawman MJP, Hughes G, Gifford GA (1987) Protection of cattle from bovine herpesvirus type 1 (BHV-1) infection by immunization with individual viral glycoproteins. Virol 159:57-66

Babiuk LA, Campos M (1992) Respiratory vaccines for farm animals. In: Peters AR (ed) Vaccines for applications. Butterworth, UK, pp 83-115 
Babiuk LA, Lewis PJ, Cox G, van Drunen Littel-van den Hurk S, Baca-Estrada M, Tikoo SK (1995a) DNA immunization with bovine herpesvirus-1 genes. In: Liu $M$ (ed) DNA vaccines: a new era in vaccinology. New York Academy of Sciences, NY, pp 50-56

Babiuk LA, van Drunen Littel-van den Hurk S, Tikoo SK (1995b) Immunology of bovine herpesvirus infections. Vet Microbiol 772:47-63

Babiuk LA, Lewis PJ, Suradhat S, van Drunen Littel-van den Hurk S, Baca-Estrada M, Tikoo SK, Yoo D (1996) Polynucleotide immunization: a novel approach to vaccination. Vaccines 96, Cold Spring Harbor, Cold Spring Harbor, NY, pp 33-38

Campos M, Bielefeldt Ohmann H, Hutchings D, Rapin N, Babiuk LA, Lawman MJP (1989) Role of interferon gamma in inducing cytotoxicity of peripheral blood mononuclear leukocytes to bovine herpesvirus type $1 \sim(\mathrm{BHV}-1)$-infected cells. Cell Immunol 120:259-269

Cox GJM, Zamb TJ, Babiuk LA (1993) Bovine herpesvirus 1: Immune responses in mice and cattle injected with plasmid DNA. J Virol 67:5664-5667

Davis HL, Michel ML, Whalen RG (1993) DNA-based immunization induces continuous secretion of hepatitis B surface antigen and high levels of circulating antibody. Hum Mol Gen 2:1847-1851

Donnelly JJ, Friedman A, Martinez D, Montgomery DL, Shiver JW, Motzel SL, Ulmer JB, Liu MA (1995) Preclinical efficacy of a prototype DNA vaccines: Enhanced protection against antigenic drift in influenza virus. Nature Medicine 1(6):583-587

Donnelly JJ, Ulmer JB, Liu MA (1993) Immunization with polynucleotides: a novel approach to vaccination. The Immunologist 2:20-26

East L, Kerlin RL, Altmann K, Watson DL (1993) Adjuvants for new veterinary vaccines. Prog Vaccin 4:1-28

Eisemann CH, Ginnington KC (1994) The peritrophic membrane: its formation, structure, chemical composition and permeability in relation to vaccination against ectoparasitic arthropods. Int $\mathbf{J}$ Parasitol 24:15-26

Felgner PL (1995) Cationic lipids for direct in vivo gene delivery. In: Liu M (ed) DNA vaccines: a new era in vaccinology. New York Academy of Sciences, NY, 772:126-139

Fynan EF, Webster RG, Fuller DH, Haynes JR, Santoro JS, Robinson HL (1993) DNA vaccines: protective immunizations by parenteral, mucosal and gene-gun inoculations. Proc Natl Acad Sci USA 90:11478-11482

Gao Y, Daley MJ, Splitter GA (1995) BHV-1 glycoprotein 1 and recombinant interleukin 1B efficiently elicit mucosal $\lg$ A response. Vaccine 13:871

Haensler J, Szoka (Jr) FC (1993) Polyamidoanine cascade polymers mediate efficient transfection of cells in culture. Biconjug-Chem 4(5):372-379

Harland RJ, Potter AA, van Drunen Littel-van den Hurk S, Van Donkersgoed J, Parker MD, Zamb TJ, Janzen ED (1992) Ale effect of subunit or modified live bovine herpesvirus-1 vaccines on the efficacy of a recombinant Pasteurella haemolytica vaccine for the prevention of respiratory disease in feedlot calves. Can Vet J 33:734-741

Ho DY (1994) Amplicon-based herpes simplex virus vectors. Methods Cell Biol 43:191-210

Hoffmann SL, Sedegah M, Hedstrom RC (1994) Protection against malaria by immunization with a plasmodium yoelei circums parazoite protein nucleic acid vaccine. Vaccine 12:1529-1533

Hughes HPA, Babiuk LA (1992a) The adjuvant potential of cytokines. Biotech Therap 3:101-117

Hughes HPA, Campos M, Godson DL, van Drunen Littel-van den Hurk S, McDougall L, Rapin N, Zamb T, Babiuk LA (1991) Immunopotentiation of bovine herpesvirus subunit vaccination by interleukin-2. Immunol 74:461-466

Hughes HPA, Campos M, Potter AA, Babiuk LA (1992b) Molecular chimerization of Pasteurella haemolytica leukotoxin to interleukin-2: effects on cytokine and antigen function. Infection and Immunity 60:565-570

Inokuma H, Kerlin RL, Kemp DH, Willadsen P (1993) Effects of cattle tick (Boophilus microplus) infestation on the bovine immune system. Vet Parasitol 47:107-118

Kerlin RL, East U (1992) Potent immununosuppression by secretory/excretory products of larvae of the sheep blowfly Lucilia cuprina. Parasite Immunol 14:595-604

Kit S, Qavi H, Gaines JD, Billinglsey P (1985) Thymidine kinase negative bovine herpesvirus type 1 mutant is stable and highly attenuated in calves. Arch Virol 86:53-83

Kit S, Sheppard M, Ichimura H, Kit M (1987) Second generation pseudorabies virus vaccine with deletions in thymidine kinase and glycoprotein genes. Am J Vet Res 48:780-793

Longley C, Axelrod H, Midha S, Kakarla R, Kogan NA, Sofia M, Babu S, Wierichs L, Walker S (1995) Conjugates of glycosylated steroids and polyamines as novel non-viral gene delivery systems. In: Liu M (ed) DNA vaccines: a new era in vaccinology. New York Academy of Sciences, NY, 772:268-270 
Lowrie DB, Tascon RE, Colston MJ, Silva CL (1994) Towards a DNA vaccine against tuberculosis. Vaccine 356:152-154

Michel MIL, Davis HL, Schleef M, Manicin M, Tiollais P, Whalen RG (1995) DNA-mediated immunization to the hepatitis B surface antigen in mice: aspects of the humoral response mimic hepatitis $B$ viral infection in humans. Proc Natl Acad Sci 92:5307-5311

Morein B, Lovgren K, Hoglund S, Sundquist B (1987) The ISCOM. An immunostimulating complex. Immunol Today 8:333-338

Nick S, Klaws J, Friebel K, Birr C, Hunsmann G, Bayer H (1990) Virus neutralizing and enhancing epitopes characterized by synthetic oligopeptides derived from feline leukemia virus glycoprotein sequence. J Gen Virol 71:77-83

Nogge G (1978) Aposymbiotic tsetse flies, Glossina morsitans morsitans, obtained by feeding on rabbits immunized specifically with symbionts. J Insect Physiol 24:299-304

Olsen CW, Corapi WV, Ngichake CK, Baines JD, Scott FW (1992) Monoclonal antibodies to the spike protein of feline infectious peritonitis virus mediate antibody dependent enhancement of infection of feline macrophages. J Virol 66:956-965

Opdebeeck JP (1994) Vaccines against blood-sucking arthropods. Vet Parasitol 54:205-222

Pastoret PP, Brochier B, Languet B, Thomas 1, Paguot A, Bauduin B, Kieny MP, Lecocq JP, DeBruyn J, Costy F, Antonine H (1988) First field trial of fox vaccination against rabies using a vaccinia-rabies recombinant virus. Vet $\operatorname{Rec} 123: 481-483$

Pedersen NC, Johnson L, Bird C, Theilen GH (1986) Possible immunoenhancement of persistent viremia by feline leukemia virus envelope glycoprotein vaccines in challenge-exposure situations where whole inactivated vaccines were protective. Vet Immuno and Immunopathol 11:123-148

Potter AA, Harland RJ (1990) Development of a recombinant subunit vaccine for Pasteurella haemolytica. American Society of Microbiology Biotechnology Conference, June 1990, Chicago, IL

Robinson HL, Hunt LA, Webster RG (1993a) Protection against a lethal influenza virus challenge by immunization with a haemagglutinin-expressing plasmid. DNA Vaccine 11(9):957-960

Robinson HL, Hunt LA, Webster RG (1993b) Protection against a lethal influenza challenge by immunization with a hemagglutinin expressing plasmid. DNA Vaccine 11:957-960

Tang DC, DeVit M, Johnston SA (1992) Genetic immunization is a simple method for eliciting an immune response. Nature 356:152-154

Theodos CM, Titus RG (1993) Salivary gland material from the sandfly Lutzomyia longipalpis has an inhibitory effect on macrophage function in vitro. Parasite Immunol 15(8):481-487

Tikoo SK, Fitzpatrick DR, Babiuk LA, Zamb TJ (1990) Molecular coloning, sequencing, and expression of functional bovine herpesvirus 1 glycoprotein gIV in transfected bovine cells. J Virol 64:5132-5142

Tikoo SK, Zamb TJ, Babiuk LA (1993) Analysis of bovine herpesvirus 1 glycoprotein gIV truncations and deletions expressed by recombinant vaccinia viruses. J Virol 67:2103-2109

Tikoo SK, Campos M, Babiuk LA (1995) Bovine herpesvirus-1 (BHV-1): Biology pathogenesis and control. Adv Virus Res 45:191-223

Ulmer J, Deck RR, DeWitt CM, Friedman A, Donnelly J, Liu M (1994a) Protective immunity by intramuscular injection of low doses of influenza virus DNA vaccines. Vaccine 12:1541-1545

Ulmer JB, Deck RR, DeWitt CM, Friedman A, Donnelly JJ, Liu MA (1994b) Protective immunity by intramuscular injection of low doses of influenza virus DNA vaccines. Vaccine 12:1541-1544

Ulmer JG, Donnelly JJ, Parker SE, Rhodes GH, Felguer PL, Dwarki VJ, Gromkowski SH, Deck RR, DeWitt CM, Friedman A, Hawe LA, Leander KR, Martinez D, Perry HC, Shiver JW, Montgomery DL, Liu MA (1993) Heterologous protection against influenza by injection of DNA encoding in viral protein. Science 259:1745-1749

Valenzuela P, Medina A, Rutter WJ, Ammerer G, Rutter BD (1982) Synthesis and assembly of hepatitis B surface antigen particles in yeast. Nature 298:347-350

van Drunen Littel-van den Hurk S, Parker NW, Massie B, van den Hurk JV, Harland R, Babiuk LA, Zamb TJ (1993a) Protection of cattle from BHV-1 infection by immunization with recombinant glycoprotein gIV. Vaccine 11:25-35

van Drunen Littel-van den Hurk S, Tikoo SK, Liang X, Babiuk LA (1993b) Bovine herpesvirus-1 vaccines. Immunol Cell Biol 71:405-42

Webster RG, Fynan EF, Santoro JC, Robinson H (1994) Protection of ferret against influenza challenge with a DNA vaccine to the haemagglutinin. Vaccine 12(16):1495-1498

Weiss WR, Berzovsky JA, Houghten R, Sedegah M, Hollingdale M, Hoffman SL (1992) A T cell clone directed at the circumosporozoite protein which protects mice against both $\mathrm{P}$ yoelli and $\mathrm{P}$ berghei. J Immunol 149:2103-2109 
Whitton IL, Sheng N, Oldstone M, McKee T (1993) A "strong of beads" vaccines, comprising linked minigenes, confers protection from lethal virus challenge. J Virol 67:348-352

Wikel SK, Ramachandra RN, Bergman DK (1994) Tick-induced modulation of the host immune response. Int J Parasitol 24:59-66

Willadsen P, Eisemann CH, Tellam RL (1993) "Concealed antigens" expanding the range of immunological targets. Parasitol Today 9:132-135

Willadsen P, McKenna RV, Riding GA (1988) Isolation from the cattle tick Boophilus microplus of antigenic material capable of eliciting a protective immunological response in the bovine host. Int $\mathbf{J}$ Parasitol 18:183-189

Williams RS, Johnston SA, Reidy M, Devit MJ, McElligott SC, Sanford JC (1991) Introduction of foreign genes into tissues of living mice by DNA-coated microprojectiles. Proc Natl Acad Sci USA $88: 2726-2730$

Wolff JA, Malone RW, Williams P, Chong W, Acsadi G, Jani A, Felgner PL (1990) Direct gene transfer into mouse muscle cells in vivo. Science 247:1465-1468

Xiang ZQ, Spitalnik S, Tran M, Wunner WH, Cheng J, Ertle HC (1994) Vaccination with a plasmid vector carrying the rabies virus glycoprotein gene induces protective immunity against rabies virus. Virology 199:132-140

Xu D, Liew FY (1994) Genetic vaccination against leishmaniasis. Vaccine 12:1534-1536

Yilma T, Hsu D, Jones L, Owens S (1988) Protection of cattle against rinderpest and vaccinia virus recombinants expressing the $\mathrm{HA}$ and $\mathrm{F}$ genes. Science 242:1058-1061

Zijl M, Wensvoort G, de Kluyver E, Hulst M, van den Gulden H, Gielkens A, Bems A, Moorman R (1991) Live attenuated pseudorabies virus expressing envelope glycoprotein El of hog cholera virus protects swine against both pseudorabies and hog cholera. J Virol 65:2761-2765 